\title{
Parents' Instrumental use of Media in Childrearing: Relationships with Confidence in Parenting, and Health and Conduct Problems in Children
}

\author{
Peter Nikken $\mathbb{1}^{1,2}$
}

Published online: 16 November 2018

(c) The Author(s) 2018, Corrected publication 2018

\begin{abstract}
Using an online questionnaire among 516 Dutch parents (children between 1 and 12 years; 68\% mothers, 18\% single parents) this study explored whether parents see media devices as useful tools in childrearing, and how parent-family characteristics and parental perceptions on parenting, media effects and child development predict the acceptance of instrumental media use. Findings revealed that parents saw media as a) a distractor providing the parent relief in childrearing, b) a babysitter when the parent is unavailable, and c) a tool to modify children's behavior. Whereas 20 to 30 percent found media useful as a modifier or babysitter, only about 10 percent perceived media helpful as a distractor. Acceptance of the different types of instrumental media use depended more on parental perceptions than on parent-family variables: i.e., instrumental use of media was primarily endorsed by parents who are less confident about their parenting, have less support from a partner, expect positive effects from the media, and report health and conduct problems in their children.
\end{abstract}

Keywords Parental mediation $\cdot$ Media as babysitter $\cdot$ Media as behavior modifier $\cdot$ Parental competence $\cdot$ Child developmental problems

Parents are essential for how children use media technologies and how media affect their development (Piotrowski et al. 2015). As such, parents can intentionally apply several strategies when guiding their children, for example, restricting children's media use; monitoring children's online whereabouts; providing active mediation; co-using media together for fun and entertainment; and supervising, i.e., let the child use a device on his or her own while keeping an eye on the child from a distance (e.g., Livingstone and Helsper 2008; Nikken and Jansz 2014; Nikken and Schols 2015). Such parental involvement, in particular restrictive and active mediation, has positive outcomes for the child's development: children will see or use less

Peter Nikken

p.nikken@windesheim.nl

1 Erasmus School of History, Culture and Communication, Erasmus University Rotterdam, P.O. Box 1738, 3000 DR Rotterdam, The Netherlands

2 Windesheim University of Applied Science, P.O. Box 10090, 8000 GB Zwolle, The Netherlands inappropriate media content, become more critical about media content, remember more educational content, and perform better at school; whereas using media together with a parent has positive effects on bonding and developing cultural tastes (Mendoza 2009).

With the ubiquitous availability of media devices and content for children, nowadays, it is impossible for parents to apply parental mediation strategies all the time. Parenting is often challenging (Crnic et al. 2005) and many parents in Western societies experience high pressure on their parenting practices, for instance, because of increases in women's labor force participation, time pressure in completing one's job or a decline in free time (Nomaguchi 2009). To reduce such stress and ease parenting, parents may be less apt to invest in parental mediation and rely more on technology to keep their children occupied. Especially when the demands in daily hassles exceed the available resources that parents have, it is understandable that parents loosen the limits on children's solitary TV viewing (Evans et al. 2011; Walton et al. 2014) or get more touchscreens at home to be used by their children (Wartella et al. 2014). Such instrumental use of media can be explained by the stress process model (Pearlin 1989), which 
posits that primary stressors, such as work overload or marital problems, create secondary stressors, such as time pressure in the parenting sphere. According to this theory, the solitary use of television or other devices by the child is seen by parents as an option to get a break from childrearing and create some time for themselves. The instrumental use of media devices in parenting can, however, also be explained by the uses \& gratifications (U\&G) theory, which specifies that individuals actively select media to fulfil particular needs (Rubin 1986). The U\&G paradigm assumes that audience members are active, in control of their media consumption, and are able to accurately report the gratifications they receive from their media consumption and why they seek these gratifications. However, the U\&G paradigm is also essentially individualistic in focus. Therefore, at first sight, the U\&G theory may not seem well suited to study parental motives for their children's media use, as the child is the targeted consumer of that media content. Yet, in the case of instrumental use of media the child's media diet is still determined by psychological beliefs, motives and needs, albeit their parents'. Thus, because the parents' selection of media devices and media content for their child is fulfilling the parent's psychological and social needs, the U\&G framework is useful to study parents' instrumental use of media for their children (Beyens and Eggermont 2014; Nabi and Krcmar 2016). Moreover, following Nabi and Krcmar (2016) the emphasis of the U\&G framework on individuals' psychological and social motives for media selection makes this framework especially well-suited to apply to the parental choice context. The decisions parents make regarding how and when they use media instrumentally in their parenting inevitably fall within the context of the parent-child relational dynamic, which implies that media choices made by parents must balance the needs of themselves and of their child's. When parents decide to let media entertain or teach their children in a certain way in case they cannot attend the child themselves, in some way they will always take the needs of their children in perception too. And that implies that characteristics of the individual child, like traits and temperaments and patterns of social behavior, will influence why parents choose to use media for their child the way that they do (Nabi and Krcmar 2016). Seen from this perspective, it is especially interesting to apply the U\&G framework when the dynamic unit of media consumption is not the individual-be it the parent or the child-but the parent and the child together as representatives of the family/household (Morley 1986, p. 15).

How media devices are used within the context of personal relationships within the family has been extensively discussed by Lull (1980a, 1980b) and Morley (1986) and their results are highly interesting for the study of instrumental use of media by parents for their children. According to Lull's ethnographic research, the use of media within the social environment of the family can be understood along two dimensions: first, media serve a structural function (i.e., providing companionship for the viewer and regulating the routines in family life: e.g., diner time, bedtime), but second, they also serve a relational function (i.e., allowing family members common ground for conversation, providing them shared experiences, presenting them with models for learning, mirroring or imitation, and allowing family members to express their ideas and to exert or undergo social dominance, e.g., parents allowing their children watch TV or use other devices). Drawing on Lull's work, Morley (1986) posits that media are always used purposefully by family members to construct the occasions of their interactions and to construct the context within they can interact (p.22). Thereby, individuals constantly exert social cultural power over each other in the sense of their gender, age and other personal characteristics, creating the family as it is together. For instance, using the TV set as a babysitter for fatigued or irritable children functions not only as a way to relief the parent's housekeeping at a certain moment, but more profoundly represents a family ritual to avoid the kind of conflict that often arises between pressured parents and tired children. Moreover, Morley also notices that families transform over time, moving through a number of stages as children grow up, each of which require restructuring the family relationships and interactions, and by that also the uses of media. That is, depending on the needs of the family unit and the members within that unit at certain times, media are used in different ways, as are decision-making procedures revised and updated according to the changing needs and contexts. With younger children at home, for instance, parents may have different motives for letting their toddlers use tablets or smartphones, than with older children who have to do homework instead of playing games with their schoolmates.

Thus, considering that differing family dynamics and different personalities within families may influence media use motives, this opens new lines of inquiry for U\&Goriented research and stresses the need to expand our understanding of the social uses of media from one in which "social" is considered a companionship motive to a perspective in which "social" reflects a dynamic between individuals with different needs and personalities within a relational context (Nabi and Krcmar 2016). Hereunder, we further address this "social use" in light of parents' instrumental use of media for their children, and then focus on parents' beliefs and parent-family background characteristics as determinants of that instrumental use of media in the social context.

Instrumental use of media is not the same as the strategy of supervision, where parents keep an eye on how their children use a device and react to media content (Nikken and Schols 2015). With instrumental use parents rather rely 
on the technology to sooth or calm their child, or to keep their child busy, for instance, because the parent cannot be physically present or has other chores to attend. Thus, in the case of instrumental use, the child is using a device often alone without parental supervision. Since solitary use may have several backdrops, parents are discouraged to use electronic devices as an instrumental tool, i.e. especially as a pacifier, in their childrearing practices (AAP Council 2016). First, relying on the all-time everywhere accessibility of screen devices enables use at any time and place, which in turn increases the chance that children will expose themselves more to media when they grow up (Cingel and Krcmar 2013). Such increased media use can in turn lead to less sleep, lower school performance, and less outdoor play etc., which is deemed not beneficial for a healthy development. Second, it is important that parents guide their children's media use actively because then children can benefit the most from educational outcomes (Rasmussen et al. 2016). Finally, media productions that children consume online can be created and uploaded by virtually anyone and are not regulated by professional production procedures. The recent Elsagate involving inappropriate YouTube video's (Satherley 2017) exemplified the particular vulnerability of unsupervised online media use, due to children's lack of technical, critical and social skills (Livingstone et al. 2011). With regard to the use of media screen time as a reward, there may be objectives too. For instance, using media as a reward or punishment is supposed to be effective only in the short-term and doesn't help children to learn how to emotionally regulate themselves in the long run. Instead, using screens as a reward or punishment tool may develop a transactional relationship between the child and parent and not stimulate the development of their intrinsic motivation.

Despite the advice to not use media as a tool in parenting, several studies indicate that when parents are not able to attend their child, they do rely on technology, often colloquially labeled as 'babysitting', to keep their children busy or entertained. For example, between 20 and 40 percent of American parents with children under 2, 6 and 8 years agreed that they then can do chores at home thanks to children's solitary screen use (Rideout and Hamel 2006; Zimmerman et al. 2007). Moreover about 50\% of American parents with children up to 12 years stated that their family benefits from using television as a babysitter (Evans et al. 2011), whereas almost all American parents with children up to 7 years old allow their child to use the parent's smartphone to keep the child occupied in the car when traveling (Chiong and Shuler 2010). Also, in European studies even 70 to 80 percent of the parents with children up to 5 and 6 years old agreed to regularly use television in their parenting practices (Beyens and Eggermont 2014; Götz et al. 2007), whereas among Israeli parents with children aged 18 to 36 months (Elias and Sulkin 2017) use of media in parenting varied from 32 percent (media during mealtimes) to 73 percent (media as babysitter).

A few studies have addressed parent's motives for their children's media use, including motives that help both the child and the parent themselves and that relate to instrumental use of media. These studies, however, do not yet provide a clear view on what instrumental use of media entails. By means of a factor analysis Gantz (1982), for example, empirically concluded that the use of media as a tool in parenting benefits three parental needs: first, unimpeded work around the house, i.e., to get children out of the parent's way when they have work to do; second, respite when parents emotionally have no power to keep their children occupied; and finally, to guarantee the parent that the child is entertained or out of trouble. Götz et al. (2007) more recently from qualitative interviews deduced that parents use media devices also for other reasons. That is, next to (a) babysitting when the parent cannot be present physically or emotionally and (b) substituting in 'emergency cases' (keep the child occupied or entertained while the parent has other chores), media may also be used for (c) distracting or calming the child, for example, when children have difficulties with eating or going to sleep or when they are over-exited, tired or frightened for a doctor's visit; and (d) as behavior modifying, for example, as a reward to stimulate good behavior in their child or as a threat to remove privileges. Finally, Nabi and Krcmar (2016) among a sample of mostly mothers with children up to six years, in a factor analysis found that media are seen as a tool to help the child relax, provide the parent some time to themselves, and to reward the child.

Since we have still little knowledge about the underlying factors that may explain parents' use of media as tools in their parenting, the present study focuses on how parent and family characteristics, together with parents' perceptions on their own parenting situation are related to the instrumental use of media in their parenting. Parental perceptions about the role of media for their children may form a first important predictor of the parents' needs to use media as a tool in their parenting. Parents who are concerned about the risks of media for children temper the presence of screens in their child's bedroom (Nikken and Schols 2015; Rideout and Hamel 2006), yet also more often use television or computers as a reward (Pearson et al. 2011). Moreover, parents who expect positive educational influences from media on their child are more apt to use television or eBooks as a babysitter in their parenting (Beyens and Eggermont 2014; Etta et al. 2018; Götz et al. 2007) and or as a tool to relax their child (Nabi and Krcmar 2016).

Another important factor in the parent-child dyadic relationship that may affect instrumental use of media is the child's temperament. Having a child with a difficult 
temperament or conduct problems may lead to less engagement in activities with that child (Giallo et al. 2013; Machida et al. 2002). In similar vein, health problems or disorders as autism or ADHD in children can also make parenting more difficult (Dodge et al. 1994). In accordance with the stress process model (Pearlin 1989), in these families media devices can provide a relief for parents to take their mind off these problems. Moreover, in line with the U\&G paradigm (Rubin 1986), it can also be hypothesized that the child's condition influences the parents' perceptions of their relational management needs which, in turn, influences how media are used: parents who perceive their children as energetic are more likely to use media to help them relax, as a reward, and to have time away from them (Nabi and Krcmar 2016). Also, very young children with poor self-regulation consume more media over time, possibly because parents try to soothe their fussy infants through screen time as a parent coping strategy (Radesky et al. 2014).

A third important factor for the instrumental use of media devices in parenting concerns how parents evaluate their own parenting, i.e., how competent they are in childrearing and how they see their relationship with other caregivers in the family. It is known that children are more likely to exceed screen-time recommendations when their parents experience low levels of self-efficacy to influence the child's physical activity or control the child's screen time (Campbell et al. 2010; Jago et al. 2015; Smith et al. 2010). Moreover, high maternal working hours create parenting time pressure and undermine mothers' well-being, which encourages children to watch more television (Beyens and Eggermont 2017). Thus parents who are less confident about their parenting may rely more heavily on media devices for their children to keep the household going. Moreover, parents who experience little support from their (ex)partner or spouse also face more difficulties in parenting than parents who can rely on a supportive partner (Gordon and Whelan-Berry 2004; McLoyd 1998). An unsupportive partner reduces the ability to parent effectively, which may lead to inconsistent or more lenient parental regulation of the child's behavior. Even infrequent disagreement between parents over media rules already matters for children's violent media use and child outcomes (Mares et al. 2018).

Finally, previous studies have shown that several demographic factors may affect the use of media as a tool in parenting. It should be noted, however, that these factors could be interrelated with parents' perceptions of the family situation, viz. difficulties in child temperament, parents' confidence in parenting, or the support from a partner in the family, as well as with parents' perceptions of how media contribute to the development of their child. For example, parents from lower social-economic strata more often use television as a babysitter (Gantz 1982) or as a bedtime ritual tool (Götz et al. 2007) than parents from higher educated or wealthier families. These findings make sense, since parents from lower strata as compared to higher educated parents usually prefer the entertainment value of media like video gaming for their children (Rideout 2017). Also, lower educated parents, in general feel that they have less control over the outcomes of child development, are more controlling and punitive than parents from higher strata, and also make less use of various possibilities to support their child's development (Hoff et al. 2002). Parenting in lower educated or low-income families, therefore, can be more strained with daily hassles than in higher educated, wealthier families (McLoyd 1998; Warren 2005), which may lead to a higher need for media technology in childrearing practices. Next, family size may also explain difficulties in parenting, which in turn increase the need to use media instrumentally in parenting. In bigger families parenting may be more demanding than in families with less children at home (Caceres-Delpiano 2006). With many children, parents may have full time jobs to support the family which puts pressure on family time (Aldous and Klein 1991) resulting in less or unequal attention to all children. This pressure may increase the need to keep the children occupied by electronic screens, although Nabi and Krcmar (2016) did not find such a relationship. In single-parent families parenting also is more demanding. Parents in single-parent families usually are not only lower educated, but also stressed by unemployment and lack support from a partner (Cain and Combs-Orme 2005; Mather 2010). Probably therefore, single-parents find it more difficult to guide their children's media use and apply mediation strategies consequently than parents in intact families (Nikken and de Haan 2015; Zaman et al. 2016). Moreover, children with a single-parent have more media devices in their bedroom and use media more on their own and for longer periods per day (Livingstone et al. 2015; Nikken 2017). With regard to the child's gender and age, differences in using media instrumentally also may be affected by how parents perceive the upbringing of their child. Parents usually find it more difficult to guide their sons than their daughters (e.g., Hoff et al. 2002), which may explain that boys more often than girls have and use media devices alone in their bedroom or are left alone with the television on in order to calm the child or to give the parent a relief or do chores (Götz et al. 2007; Rideout and Hamel 2006). Among younger children, Nabi and Krcmar (2016), however, found the opposite: media were more often used as a tool to provide the parents some time for themselves when they were raising girls. Also, in general, parenting of younger children is more demanding than of older children, which concurs with findings that relate age to the instrumental use of media. Gantz (1982) and Pearson et al. (2011), for example, reported that among older children, 
i.e., about 9 to 12 years old, television or computers are less often used as a reward or as a babysitter as compared to younger children, i.e., about 2 to 5 years. In similar vein, Götz et al. (2007) reported that parents more often use television as a babysitter with children aged 4 to 5 years old than with younger children, whereas Nabi and Krcmar (2016) found such a relationship with age for the use of media as a reward for children. Thus, instrumental use of media seems to peek among children of about 5 years old, possibly because these children put higher demands on their parents. Finally, the parent's gender may be a fifth factor that affects parental needs. Mothers typically participate in childrearing activities at a significantly higher rate than fathers (Bornstein et al. 2003; McBride and Mills 1993). Therefore, fathers have less experience with parenting and as a result may be more inclined to perceive media devices as handy in parenting than mothers do. Nikken and de Haan (2015) indeed noticed that fathers tend to experience more problems in mediating their children's media use than do mothers.

Using a survey among Dutch parents with children aged 1 to 12 years, this study first explores empirically whether different types of instrumental use of media in parenting can be discerned $\left(\mathrm{RQ}_{1}\right)$. The rationale behind this research question is that there seems to be no consensus yet on the different types and associated functions of instrumental media use in childrearing. Only Gantz (1982) and Nabi and Krcmar (2016) empirically tested which types of needs media fulfil. In addition, this study will test the extent that these parents (dis)agree with the instrumental use of media in their parenting $\left(\mathrm{RQ}_{2}\right)$. Finally, we look at which parent and family background variables, together with the parent's views on the parenting of their child, explain the parent's endorsement of instrumental use of media. Based on the discussed literature, it is assumed that parents more strongly will favor instrumental media use for boys than for girls $\left(\mathrm{H}_{1}\right)$ and for children around 5 years of age, as opposed to younger children and older children up to 12 years of age $\left(\mathrm{H}_{2}\right)$. Also, fathers will be more inclined to make use of media than mothers $\left(\mathrm{H}_{3}\right)$, as will parents in lower educated, single, and bigger families as compared to parents in higher educated $\left(\mathrm{H}_{4}\right)$, intact $\left(\mathrm{H}_{5}\right)$, and smaller families $\left(\mathrm{H}_{6}\right)$. Furthermore, with regard to the parent's views on parenting, parents will be less favorable towards the instrumental use of media when they believe that media have negative effects on children $\left(\mathrm{H}_{7}\right)$, whereas they will be more favorable about instrumental media use when they believe in positive media effects $\left(\mathrm{H}_{8}\right)$, and when their children have developmental issues, such as health or conduct problems $\left(\mathrm{H}_{9}\right)$. Also, it is expected that parents more often turn to media when they lack support from a spouse or (ex)partner $\left(\mathrm{H}_{10}\right)$ or, finally, when they have less confidence in their own parenting practices $\left(\mathrm{H}_{11}\right)$.

\section{Method}

\section{Participants}

In the autumn of 2014 about 2.000 parents in the Netherlands with children between 1 and 12 years were contacted online by a professional marketing research bureau. The parents were pooled from a large database of respondents who had agreed to participate in (online) research and were paid a small incentive for cooperating. The study deliberately also included families with older children, that is up to 12 years, in order to look for differences in instrumental use of media between younger and older children. In all, 516 parents reacted (response rate about 26\%), of which two thirds $(68.2 \%)$ were mothers. About one in five parents (18.2\%) reported to be a single parent, whereas the other respondents represented an intact family. The respondent's education was measured as one of 7 types in the Dutch educational system and then recoded into 3 consecutive levels; as compared to the Dutch population (CBS 2014), $54.1 \%$ of the sample (versus $63 \%$ ) had a level equal to prevocational secondary education or less (aggregated types 1 up to 4), $39.2 \%$ (versus $27 \%$ ) had a level equal to senior general secondary education (aggregated types 5 and 6 ) and $6.8 \%$ (versus 9\%) had a university (master, $\mathrm{PhD}$ ) educational level (type 7). Respondents reported the age of the oldest child living at home. To realize an even spread of families with children up to 4 years, between 4 and 6 years, between 7 and 9 years, and between 10 and 12 years, respondents were stratified on the age of their reference child such that each of the four age categories represented about $25 \%$ of the sample. There were somewhat more sons (55.8\%) than daughters and almost half of the parents $(45.2 \%)$ indicated that they had only one child living at home, whereas another $43 \%$ said they had two children. The remaining parents $(11.8 \%)$ indicated that they had three or more children living at home.

\section{Procedure}

The contacted parents were informed about the general aim of the study, i.e., an investigation about the use of media in the home, parents' views on guiding their children's media use and parenting in general, and various sources that provide parenting support. After consent, parents were presented an extensive online questionnaire pertaining to these topics, and instructed to keep their oldest child in mind who was 12 years or younger and living at home when answering all questions. Answering of the questions for the variables that are used in the present study took about $20 \mathrm{~min}$ for most of the parents.

The questions and themes in the questionnaire were partly based on a preliminary qualitative pilot study with 8 
families who had children between 18 months and 12 years. Interviewed parents in these families represented single and intact families, higher and lower educated families, and families with different cultural backgrounds, for example, Turkish nationality. The interviews took between 60 and $80 \mathrm{~min}$ and were based on a topic list, referring to media effects, media use rituals at home, and the need for face-toface or print/online support on parental mediation. Both the interview and survey were executed in agreement with the ethical standards at the universities of the investigators.

\section{Measures}

Acceptance of instrumental use of media in parenting was established by means of 8 statements about the use of media devices in the interest of the parent, the child or both (see the results for the individual items). The statements were based on the qualitative pilot study and former research into the use of media technology by parents in their parenting practices. Moreover they were congruent with the main types of instrumental use proposed by Götz et al. (2007), i.e., as a babysitter when not present, as a substitute when not available, as a distractor when tensed, or as a modifier of behavior. The respondents indicated for each statement whether it described their parenting practices on a five-point Likert scale varying from 'fully disagree' to 'fully agree'.

The parent's views about confidence in their own parenting were measured with 15 statements taken from the Dutch NOSI (Nijmeegse Ouderlijke Stress Index), a validated instrument containing 13 subscales to measure whether parents with children from 2 to 13 years old experience shortcomings in their daily parenting practices (de Brock et al. 1992). The subscale we used, taps whether parents are confident or insecure about their daily parenting practices. Items are, for example, 'raising a child is more difficult than I expected', 'on average I think that I am not such a good parent' or 'as a parent I often doubt whether I can handle each situation'. Answering options varied on a five-point Likert scale ranging from 'fully disagree' to 'fully agree'. An exploratory factor analysis with oblique rotation (i.e., direct Oblimin) showed that 12 items defined one factor indicating a lack of confidence in parenting, whereas the three remaining items conversely indicated confidence in parenting $(\mathrm{KMO}=0.94)$. Since we were interested in the use of media when parenting is difficult we averaged the 12 items that tapped a lack of parenting confidence into one scale.

Partner support was measured with a subscale adopted from the Dutch VOBO-instrument (Vragenlijst Onvervulde Behoefte aan Opvoedingsondersteuning). This instrument is now adapted to the Structured Problem Analysis of Raising Kids/SPARK (Staal et al. 2011). Respondents indicated for 6 statements (for example, 'regarding the education of my child I always feel myself supported by my (ex)partner') to what extent it was applicable to their situation. Answering options varied on a five-point Likert scale from 'fully disagree' to 'fully agree'. Exploratory factor analysis indicated that all items loaded on one factor, which were averaged into one scale.

Views on media effects were measured by means of 31 statements about positive and negative outcomes of media use for children. Respondents indicated whether this outcome was applicable to the reference child, with answering options on a five-point Likert scale varying from 'fully disagree' to 'fully agree'. The statements were based on various well known media-effect reviews and on the interviews in the qualitative pilot study and related to cognitive, social-emotional and behavioral outcomes. An exploratory factor analysis with oblique rotation (i.e., direct Oblimin, $\mathrm{KMO}=0.93$ ) revealed that the statements loaded on five factors, although in the first run several items had either low loadings $(<0.40)$ or loadings higher than 0.40 on multiple factors. After elimination of these items a solution was found with five distinct factors with items loading higher than .45 (Tabachnick and Fidell 2007). By averaging the respondent's scores on the items of the respective factors in this solution, the following five scales were constructed: (1) positive effects on learning (5 items, for example, 'my child can learn about the world via media'; or 'my child may know more about politics thanks to the Children's News'); (2) positive effects on social skills (4 items, for example, 'my child may improve his or her social skills by the use of media'; or my child can increase his or her peer group with good friends via social media'); (3) positive effects on emotions ( 5 items, for example, 'my child can become calm and quiet from media use'; or 'my child can learn to improve his or her concentration by using media'); (4) negative effects on behavior (5 items, for example, 'my child may adopt rude language from the media'; or 'my child my get aggressive from seeing violence in the media'); and (5) negative effects on health (5 items, for example, 'my child may get obese from media use'; or 'my child may develop sleeping problems because of media use').

Child developmental problems were established by asking the parents whether to some extent they experienced 13 potential difficulties in the upbringing of their child. The statements, again adopted from the VOBO/SPARK-instrument (Staal et al. 2011), related to several problematic issues in children, such as not following rules and regulations, bad eating habits, lack of friendships, troubles at school, disturbances in emotions, or problems with physical health or leisure activities. In line with the VOBO/SPARK, answers were coded as 'not applicable' (coded as 1), or 'applicable, ... but not difficult to handle at all' (2) up to 'applicable ... and very difficult to handle' (5). An 
exploratory factor analysis with oblique rotation (i.e., direct Oblimin; $\mathrm{KMO}=0.94$ ) indicated that parents are confronted with three types of problems in their child's development: (1) health issues (4 items, for example, 'difficulties with personal hygiene or toilet training'; or 'with exercise and health'), (2) social-emotional problems (7 items, for example, 'blending in at school'; 'dealing with emotions as fright and anger'; or 'being accepted by friends'), and (3) conduct problems ( 2 items; 'having tantrums/showing obstinate behavior'; and 'impudent/big talk'). All items had loadings higher than 0.45 on their respective factors only (Tabachnick and Fidell 2007) and were averaged into the three respective scales.

\section{Data analyses}

Table 1 gives an overview of the psychometric values of all concepts that were used in the present study, as well as the zero-order correlations between these variables. The types of instrumental media use were established by means of an exploratory factor analysis (SPSS 24), whereas absolute differences in acceptance of these types of instrumental use for the parent-family background variables were tested with ANOVA's. Since an inverted u-shaped relationship thereby was expected for the child's age, children were categorized as up to 4 years, between 4 and 6 , between 7 and 9 , or between 10 and 12 years. Hierarchical linear regression analyses, finally, were used to inform which parent-family background characteristics and which parental views predicted the acceptance of instrumental use of media in parenting. In all regression analyses a 2-step model was used. The variables that measured parental views were entered in the second step, to test if these variables influenced the importance of the parent-family background variables when predicting the instrumental use of media in parenting.

\section{Results}

\section{Types Of Instrumental Media Use}

An exploratory factor analysis with oblique rotation (i.e., direct Oblimin) was used to verify whether the eight examples of instrumental use of media represent different types $\left(\mathrm{RQ}_{1}\right)$. The analysis resulted in three unique factors, all with loadings higher than .45 (Tabachnick and Fidell 2007), and explained 67.2 percent of the variance (KMO $=.85$ ). The first factor contained 4 items relating to media as a distractor that provides relief for the parent ('I like watching tv/dvd during dinner as it helps me to let my child eat better', 'when my child uses media, I can take my mind off parenting for a while', 'a tv or computer of his/her own in the bedroom gives me rest in the housekeeping' and 'an electronic screen is a handy tool when I put my child to bed'). The second factor was comprised by 2 items relating to modifying the child's behavior ('no tv or computer as a punishment helps my child better obey' and 'media are handy as a reward for my child when he/she behaves well'). The third factor, finally, was comprised by the items which related to media use as a babysitter occupying the child ('media are a convenient babysitter for me when my child is alone for a while' and 'media are convenient to keep my child busy'). Based on the factor analysis three scales were created by averaging the items that loaded on media use as, respectively, a 'distractor', a 'modifier' and a 'babysitter'.

\section{Acceptance Of Instrumental Media Use By Parent And Family Characteristics}

Figure 1 presents the distribution of the answers for all instrumental media use items per scale. As shown, only a minority of parents was positive about media as a distractor, modifier or babysitter in their parenting practices $\left(\mathrm{RQ}_{2}\right)$. About 1 in 10 parents agreed with the idea to use media as a distractor for relief, whereas about 20 to 30 percent of the parents agreed with media as a modifier of behavior or as a babysitter to keep their child occupied. Conversely, 20 to 50 percent of the parents rejected the use of media as a babysitter, 40 percent disagreed with media as a modifier, and about 70 percent disagreed with media as a distractor in parenting. When comparing the parents' mean scores for the three types of instrumental media use, it shows that parents accepted the use of media as a distractor in their parenting the least $(M=1.98)$. Yet, they were significantly more positive about media as a babysitter $(M=2.68)$ and as a modifier for their child's behavior $(M=2.76)$, Student's $t$ $(515)=$ respectively 18.82 and $19.82 ; p<.001$. Both differences were large considering that Cohen's $d=$ respectively .87 and .83 .

Table 2 presents the absolute scale scores for the three types of instrumental media use and the $F$-values found in the ANOVA's for the child's age level and gender, the parent's gender, educational level and marital status, and family size. As shown, parents found media significantly more acceptable as a modifier of behavior for their sons than for their daughters, though parents did not differentiate between sons and daughters in using media as a distractor or as a babysitter. Thus $\mathrm{H}_{1}$ is partly confirmed. With regard to the child's age, parents most often accepted media devices as a modifier and as a babysitter for children between 4 and 6 years. However, they equally often agreed on these types of instrumental use when their children are between 7 and 9 years, and to some extent also when they are between 9 and 12 years. Thus $\mathrm{H}_{2}$ is only partly confirmed. Next, as expected, fathers significantly more often agreed with the use of media as a distractor and as a babysitter, as compared 


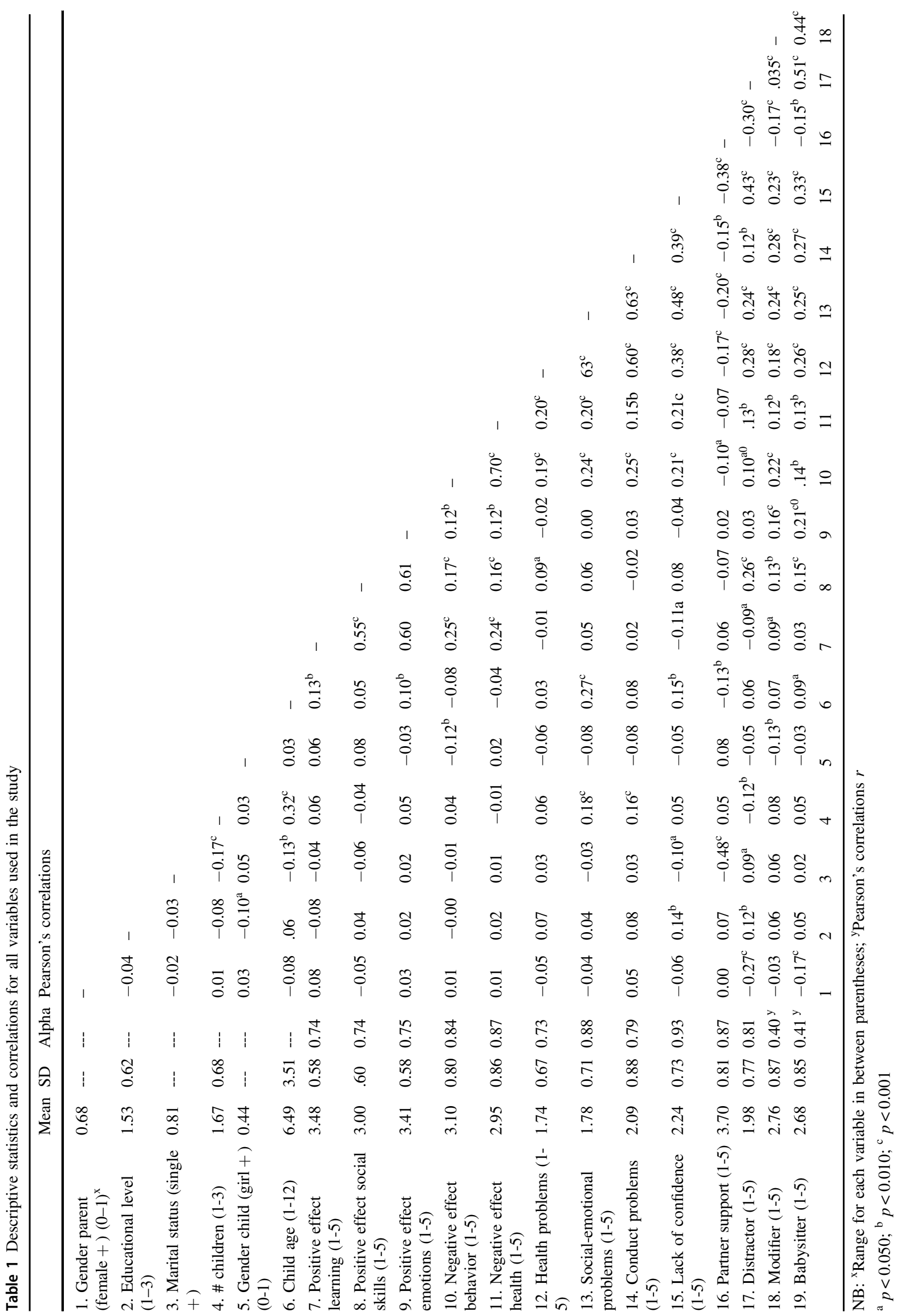




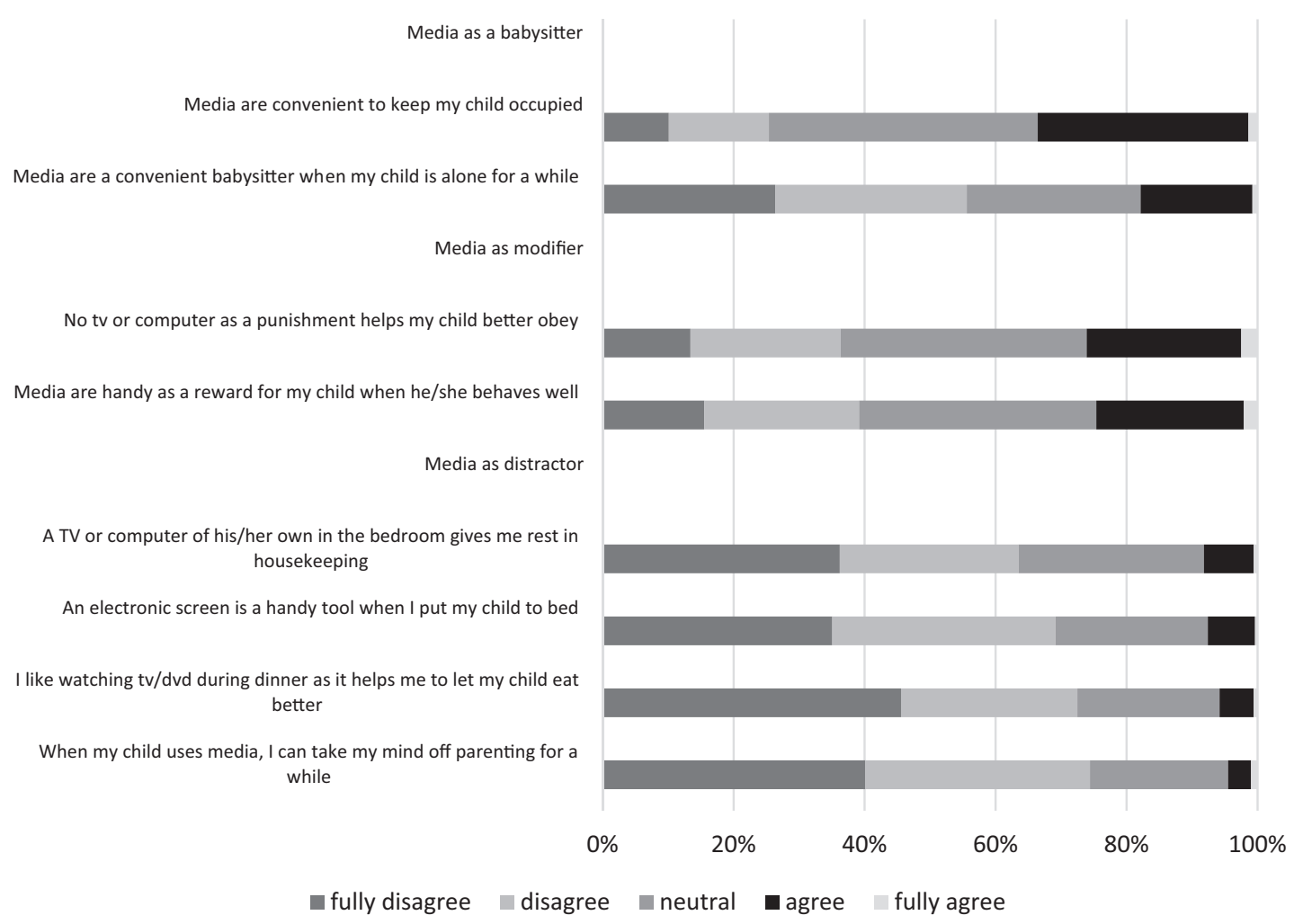

Fig. 1 Extent to which parents endorse three types of instrumental use of media in their parenting

to mothers, confirming $\mathrm{H}_{3}$. Also as expected, lower educated and single parents agreed more with the use of media as a distractor for relief as compared to higher educated and cohabitating parents. Acceptance of the other two types of instrumental use, however, did not differ with educational level or marital status, thus $\mathrm{H}_{4}$ and $\mathrm{H}_{5}$ are both partly confirmed. Finally, family size matters for accepting media as a distractor and as a modifier in an absolute sense. As predicted by $\mathrm{H}_{6}$, with more children at home parents significantly more often agreed using media as a modifier of their child's behavior. Yet, they also significantly less often agreed to use media as a distractor for relief, contradicting $\mathrm{H}_{6}$.

\section{Relative Differences Between Parents}

In order to control for interrelationships between the parent and family background characteristics and to test whether parental beliefs about media effects, the child's development, and the parent's parenting are also related to the acceptance of instrumental media use, hierarchical regression analyses were performed. The parent-family characteristics were entered in a first step, whereas the parental views were entered in a second step. Table 3 presents the standardized beta-values and the explained variance of both steps, for each type of instrumental media use. As can be seen, entering the parent's views in the second step had an important effect on the amount of variance explained, adding 25, 10 and 17 percent for media used as, respectively, a distractor, modifier, and babysitter. The parent's views thus are very strong predictors of the acceptance of media as tools in parenting, more so than parent-family characteristics.

With regard to the parent-family characteristics, all model I analyses basically present the same pattern as appeared from the separate ANOVA's in Table 2. Only marital status no longer appeared to be a significant predictor of the acceptance of media as a distractor, thus no longer supporting $\mathrm{H}_{5}$, whereas family size also no longer was associated with media as a modifier $\left(\mathrm{H}_{6}\right)$. Moreover, age of the child was now only marginally associated with the use of media as a babysitter $\left(\mathrm{H}_{2}\right)$. However, when adding the parental views on media effects, problems in child development, and the parent's own parenting in the model II analyses, a few shifts are noticeable among the parent-family characteristics. First, educational level was no longer a significant predictor of the acceptance of media as a distractor. Yet, higher educated parents now significantly more often agreed with the use of media as a babysitter than did lower educated parents, contradicting $\mathrm{H}_{4}$. Second, the child's age did not predict the acceptance of media as a modifier or as a babysitter any more, thus $\mathrm{H}_{2}$ is not supported either. 
Table 2 Absolute differences in acceptance of instrumental use of media by parent's gender and education, marital status, family size, and child's gender and age

\begin{tabular}{|c|c|c|c|c|c|c|}
\hline \multirow[t]{2}{*}{ Instrumental media use as } & \multicolumn{2}{|c|}{ Distractor } & \multicolumn{2}{|c|}{ Modifier } & \multicolumn{2}{|c|}{ Babysitter } \\
\hline & $M$ & $F(\mathrm{df})$ & $M$ & $F(\mathrm{df})$ & $M$ & $F(\mathrm{df})$ \\
\hline Fathers & $2.29^{\mathrm{a}}$ & $41.72 * * *(1514)$ & 2.79 & NS & $2.89^{\mathrm{a}}$ & $14.46^{* * *}(1514)$ \\
\hline Mothers & $1.84^{\mathrm{b}}$ & & 2.74 & & $2.58^{\mathrm{b}}$ & \\
\hline Educ. low & $2.05^{\mathrm{a}}$ & $3.95 *(2513)$ & 2.79 & NS & 2.64 & NS \\
\hline Educ. middle & $1.94^{\mathrm{ab}}$ & & 2.76 & & 2.74 & \\
\hline Educ. high & $1.69^{\mathrm{b}}$ & & 2.50 & & 2.70 & \\
\hline Cohabiting & $1.95^{\mathrm{a}}$ & $4.13^{*}(1514)$ & 2.73 & NS & 2.67 & NS \\
\hline Single & $2.12^{\mathrm{b}}$ & & 2.87 & & 2.71 & \\
\hline 1 child & $2.01^{\mathrm{a}}$ & $3.45^{*}(2513)$ & $2.65^{\mathrm{a}}$ & $3.54 *(2513)$ & 2.63 & NS \\
\hline 2 children & $1.93^{\mathrm{ab}}$ & & $2.87^{\mathrm{b}}$ & & 2.71 & \\
\hline $3+$ children & $1.82^{\mathrm{b}}$ & & $2.75^{\mathrm{ab}}$ & & 2.74 & \\
\hline Boys & 2.02 & NS & 2.85 & $8.53 * *(1514)$ & 2.70 & NS \\
\hline Girls & 1.93 & & 2.63 & & 2.65 & \\
\hline $0-3$ years & 1.94 & NS & $2.56^{\mathrm{a}}$ & $4.85 * *(3512)$ & $2.51^{\mathrm{a}}$ & $2.64 *(3512)$ \\
\hline 4-6 years & 1.93 & & $2.92^{\mathrm{b}}$ & & $2.77^{\mathrm{b}}$ & \\
\hline 7-9 years & 2.04 & & $2.88^{\mathrm{b}}$ & & $2.76^{\mathrm{ab}}$ & \\
\hline $10-12$ years & 2.01 & & $2.68^{\mathrm{ab}}$ & & $2.68^{\mathrm{ab}}$ & \\
\hline
\end{tabular}

NB: ${ }^{\text {a,b }}$ Values with different superscripts per column indicate significant differences

$* p<0.050 ; * * p<0.010 ; * p<0.001$
With regard to the parental views on the effects of the media, only one relationship for negative effects was significant: parents who expect such effects of media use on their child's behavior more often use media as a modifier, contradicting $\mathrm{H}_{7}$ for that type of instrumental media use. Also, contradicting $\mathrm{H}_{8}$, parents who expected positive learning outcomes of media for their child less often agreed with using media as a distractor and as a babysitter. Positive attitudes towards effects on the child's social skills and on their emotions were, however positively related, respectively, to the use of media as a distractor, and the use as a modifier and babysitter, confirming $\mathrm{H}_{8}$. Next, problems in child development also were related to the instrumental use of media. Confirming $\mathrm{H}_{9}$, parents more often agreed that media function as a distractor for relief in parenting when their child had health problems, whereas parents more often agreed with media as a modifier or as a babysitter, when their child had conduct issues. Finally, parents who received less support from a spouse or partner agreed more with media use as a distractor, confirming $\mathrm{H}_{10}$, whereas the parent's lack of confidence strongly paralleled the acceptance of media as a distractor and as a babysitter in parenting, and marginally was associated with media as a modifier, all confirming $\mathrm{H}_{11}$.

\section{Discussion}

The present study aimed to shed more light on the instrumental use of electronic media devices by parents in their childrearing practices, guided by the stress process model (Pearlin 1989) which posits that primary stressors, such as work overload or marital problems, create secondary stressors in the parenting sphere such as time pressure, and by Rubin's (1986) uses and gratifications (U\&G) notion that media technology fulfils specific needs for media users. This study relates parents' instrumental use of media with parental perceptions on the effects of media, developmental problems, confidence in childrearing, and support from an (ex)partner. As such it is possible to gain more insight into how media use choices are made within the social context of the family, and how perceptions on the needs of the individuals within that context, in this case both the parent and the child, affect such choices. This study, therefore, helps to extend the standard U\&G framework beyond its individualistic focus. Moreover, the data also provide some interesting findings with implications for future research and for improving parent advice about children and media.

With regard to the instrumental use of media in parenting, the present study suggests that parents perceive three different types of use. Though this study only used 8 items to measure instrumental media use, the three types do concur with former classifications $\left(\mathrm{RQ}_{1}\right)$. Moreover, each type also distinctly relates to situational background characteristics within the family and to the parents' perceptions of media effects, their child's development and their own parenting situation $\left(\mathrm{H}_{1-11}\right)$.

Media devices can first serve as a 'distractor' or calming tool for the child that creates relief for the parent. This type resembles types formerly labeled 'respite' (Gantz 1982) and 
Table 3 Prediction of endorsement of instrumental use of media by demographic characteristics, and parental views on media, their children's development, and parenting (standardized beta-values)

\begin{tabular}{|c|c|c|c|c|c|c|}
\hline \multirow[t]{2}{*}{ Instrumental use as } & \multicolumn{2}{|l|}{ Distractor } & \multicolumn{2}{|l|}{ Modifier } & \multicolumn{2}{|c|}{ Babysitter } \\
\hline & I & II & $\mathrm{I}$ & II & $\mathrm{I}$ & II \\
\hline Parent gender $($ female + ) & $-.27 * * *$ & $-.22 * * *$ & -.02 & -.03 & $-.15^{* *}$ & $-.14 * * *$ \\
\hline Educational level & $-.12 * *$ & -.03 & -.07 & -.03 & .04 & $.11^{*}$ \\
\hline Marital status $(1=$ single $)$ & -.06 & .04 & -.06 & -.02 & .00 & .02 \\
\hline \# Children at home & $-.11 *$ & $-.11 * *$ & .06 & .02 & .01 & -.02 \\
\hline Child gender $($ female + ) & -.03 & -.03 & $-.10^{*}$ & -.06 & -.02 & .01 \\
\hline Child $1-3$ years $^{\mathrm{a}}$ & -.02 & -.02 & $-.14^{*}$ & -.09 & $-.11 \sim$ & -.07 \\
\hline Child 7-9 years ${ }^{\mathrm{a}}$ & .02 & -.02 & .02 & -.04 & .01 & -.04 \\
\hline Child $10-12$ years & .03 & .01 & $-.11 *$ & -.09 & -.04 & -.01 \\
\hline Positive effects on learning & & $-.19 * * *$ & & -.03 & & $-.13^{*}$ \\
\hline Positive effects on social skills & & $.32 * * *$ & & .04 & & .02 \\
\hline Positive effects on emotions & & -.02 & & $.13^{*}$ & & $.28 * * *$ \\
\hline Negative effects on behavior & & -.02 & & $.16^{*}$ & & .03 \\
\hline Negative effects on health & & .05 & & -.06 & & .03 \\
\hline Health problems & & $.14 * *$ & & -.03 & & .09 \\
\hline Social-emotional problems & & .04 & & .05 & & -.01 \\
\hline Conduct problems & & -.08 & & $.16^{* *}$ & & $.13^{*}$ \\
\hline Lack of parenting confidence & & $.27 * * *$ & & $.09 \sim$ & & $.23 * * *$ \\
\hline Partner support & & $-.15 * *$ & & -.07 & & -.03 \\
\hline$F$ & $7.80 * * *$ & $16.42 * * *$ & $3.21 * * *$ & $5.31 * * *$ & $2.71 * * *$ & $8.21 * * *$ \\
\hline$R^{2}$ & .10 & .35 & .03 & .13 & .03 & .20 \\
\hline
\end{tabular}

$\sim p<0.100: * p<0.050 ; * * p<0.010 ; * * * p<0.001$

'time to self' (Nabi and Krcmar 2016). The use of media as a distractor seems somewhat more focused on the needs of the parents themselves, since this type of use was not only endorsed by fathers and parents who are uncertain about their parenting skills, but also by parents who lack support from an (ex)partner and when there is only one child at home and no siblings to keep the child occupied, and to some extent by single parents. In addition, parents used media as a distractor both for older and for younger children, which also indicates that the parent's motives prevail over the child's needs. Media are thus especially used as a distractor in the family, when parents feel that it is difficult to keep the household going by themselves. For these troubled parents media devices can provide an easy way out to get some respite, which corroborates work by Conners et al. (2007) who reported that children watch more television and more inappropriate content when their parents have depressive symptoms and lack the energy to parent. Media as a distractor was also endorsed by parents who have children with health problems, such as troubled eating habits, irregular sleep, overweight or hygiene problems, and who expect that media benefit their child's social skills, though not necessarily expect that media also educate them.
Perhaps these parents motivate their choice to use media as a distractor and get extra time for themselves by the expectation that their troubled child becomes more socially adapted and will fit in with other children more easily because of their media use.

Media can also be used as a 'babysitter' to keep the child occupied when the parent is physically absent or occupied by other tasks. This type resembles Gantz's (1982) 'unimpeded work around the house' and Nabi and Krcmar's (2016) 'relax the child' types. Within the social parent-child relationship the 'babysitter' type of use is perhaps less focused on the parent's own emotional needs, but more on practical needs: the child has to be occupied so that the parent has time to do his or her own chores. In terms of these practical needs, especially fathers, less confident parents, parents who have a child with conduct problems, and to a lesser extent parents of children aged 4 to 9 years were more apt to accept electronic screens as a useful surrogate nanny that occupies the child when the parent has other chores to attend. In accordance with Beyens and Eggermont (2014; 2017) and Etta et al. (2018), media technology was also seen as a useful babysitter by higher educated parents, and by parents who expect positive 
emotional outcomes from media use in their child. The higher television use by children who are low in agreeableness or conscientiousness and high in emotional instability, as reported by Persegani et al. (2002), could thus be the result of their parents' deliberate use of media as a babysitter, as they hope that media may affect these children's emotions and or behavior positively. Higher educated parents may be occupied more by work or other chores than lower educated parents and see less alternatives to occupy their children, and perceive screens as the most easy or cheapest option to satisfy their children. It could, however, also be the result of the higher educated parents' perception that their children are entitled to the newest technology, even though they may not feel at ease with their decision to rely on that technology (Götz et al. 2007; Livingstone et al. 2015).

Finally, media can be used as a 'modifier' of the child's behavior, which corroborates the 'reward' type mentioned by both Götz et al. (2007) and Nabi and Krcmar (2016). This type of use is, however, not restricted to rewarding, but also comprises media as a punishment, and especially addresses parents who have children with conduct problems, and who are convinced that media can affect their children, both emotionally and behaviorally. Also, media tend to be more often used as a modifier when the child is a boy, or between 4 and 9 years of age, whereas confidence in parenting was not specifically related. This indicates that in essence all parents may believe that rewarding or punishing their child by means of withholding or providing media devices can have a positive impact on their child's behavior, though parents with children with conduct problems or with children who are in a specific age range believe so even stronger. Since boys and children with conduct issues can be more demanding for parents (e.g., Hoff et al. 2002), it is understandable that parents in these cases intentionally use devices as an extension of their influence towards their child aiming to learn them the rules of family life (Pearson et al. 2011). The same applies to children in middle childhood, who can be more demanding for all parents, since they are less autonomous than older children, yet more self-reliant and inquisitive than toddlers or infants.

The three types of instrumental use were endorsed 'only' by about 1 in 10 to 1 in 3 parents. Dutch parents more often disagreed than agreed with the idea that media are useful tools in their parenting $\left(\mathrm{RQ}_{2}\right)$. This low endorsement of media as a distractor, babysitter or modifier differs from some former European and American studies, which reported that between 30 and 80 percent of the parents use media, mostly television, as a tool in parenting (e.g., Beyens and Eggermont 2014; Elias and Sulkin 2017). The low acceptance in this study may, however, be a conservative indication. First, the data were collected in 2014. Since then, the prevalence of smartphones and tablets in households and the offering of apps aimed at children has increased steadily in Western societies (e.g., Ofcom 2017). Therefore, parents nowadays may rely more on media devices to keep their child busy. Also, as Tourangeau and Yan (2007) propose, in social research some questions can be more sensitive than others. Since parenting in the Netherlands is associated with more perceived social pressure on being an involved and responsible parent (Acosta and Hutchinson 2017), parents in this study may have been reluctant to admit that media are useful as a distractor or babysitter, or as a tool to modify their child's behavior. This study had no measures to tap social desirability among the respondents, but perhaps specifically mothers felt this social pressure and therefore more often disagreed with instrumental use of media than fathers did.

Despite the relative low endorsement of instrumental media use, the results do underline that within the U\&G framework a focus on the interrelated needs of multiple individuals within a relational social unit, like the family, is a valuable approach (cf. Nabi and Krcmar 2016). As expected, parental motives for choosing media for the child, be it as a distractor, babysitter or modifier, distinctly coincided with specific parental beliefs about media and the child, and about the parent's own parenting situation. As a matter of fact, these parental beliefs were much more decisive for the use of media to alleviate childrearing, occupy the child, or to mold their behavior, than the family's demographic background variables. This finding corroborates Morley's (1986) notion that families purposefully construct the occasions of their media interactions, and the context in which they interact, on the basis of their collective needs and interests, rather than on characteristics like their social or economic class. In other words, the variety in types of media uses may be greater within these classes or strata than between. Future studies on the family's media usage should, therefore, focus more on the experience of parenting itself and what makes childrearing difficult or easy for parents than just demographic factors, as suggested by Piotrowski et al. (2015).

The results of this study also indicate that the multifaceted concept of parental mediation (e.g., Livingstone and Helsper 2008; Nikken and Jansz 2014) may be broadened by incorporating the instrumental use of media too. Within the parent-child dyadic relationship, parents intentionally can apply parental mediation strategies and help to create the media-environment that children are growing up in, but they also may use media devices intentionally as tools in their childrearing. Future studies on parental mediation should, thereby, no longer just colloquially refer to media as a babysitter, since that is a too broad concept which does not do justice to why parents rely on technology in their parenting. Studies on parental mediation should rather explore the various needs that instrumental use of media in 
parenting fulfils for childrearing, for instance, by extending the limited scales that appeared from this study. Screens may, for example, be condoned as an escape for children in households where parental disparity and family conflicts are at stake, to mask or compensate the emotional tensions that may exist between parents (Mares et al. 2018). Also, parents may rely on devices to educate their child about themes the parents has little knowledge of, or regulate routines in their family when they have siblings with different developmental levels and different demands. Moreover, these future studies may also explore whether children use media devices on their own because they themselves take the initiative or whether their parents do so when they want their child to be entertained or occupied. More precise measurements could be realized of the actual moments that individuals in the family make use of media devices, whether that use is mutual or supervised or solitary, and who initiated that use. As Beyens and Eggermont (2017, p.708) concluded in their paper, a life logistics approach incorporating elements of the $U \& G$ theory (Rubin 1986) and the stress process model (Pearlin 1989), may be a promising direction for such research.

The fact that some parents implement devices to modify their child's behavior or occupy the child when parents have no time or when they lack energy, warrants for close attention in parenting advice. In general, parents are advised to not use media technology as a pacifier without being involved in the child's media usage (e.g., AAP Council 2016). Though this advice makes perfectly sense considering the risks for child development, in practice parents do rely on technology in their parenting for various reasons. The positive side of applying devices as a tool may be that the parent feels relaxed and can be more involved with their child at other times (Gantz 1982). Modern technologies and platforms like YouTube make it indeed very easy for parents to rely on; the technology is based on a simple user interface that allows children to consume video after video from an endless playlist or see the same content over and over again thanks to the repeat function. In addition, mobile screens can be used anywhere inside and outside the house, so that children do not have to be in the vicinity of the parent when parents let them use media to have some respite or time to attend to other tasks. Thus, when appropriately applied, instrumental use of media can benefit several members within the family at the same time. A risk of relying too much on technology may be, however, that children will use media too often alone without an attentive parent. As this study showed, especially among less confident parents for whom regulating the child's physical activity or sedentary behavior is difficult (Campbell et al. 2010; Jago et al. 2015; Smith et al. 2010) this is a serious risk. The use of electronic devices as a babysitter may increase the habitual use of technology at home (Elias and
Sulkin 2017), which in turn may lead to more media usage at older ages (Cingel and Krcmar 2013). Moreover, using tablets or television programs to keep the child occupied may decrease valuable opportunities for direct contact and interaction between parent and child, which may have negative effects for the child's development, for example, in domains of social skills or language development. Using devices alone during bedtime, and probably also in bed, furthermore, may supplant reading books and may lead to a later onset of sleep and less sleep overall (Cheung et al. 2017). Using media as a distractor or as a babysitter may also lead to consuming content which is not appropriate, as parents may not actively look for educational content, but rather just rely on entertaining productions (Elias and Sulkin 2017). Also, solitary use means that there are less opportunities for co-using educational media content which benefits children (Rasmussen et al. 2016). Finally, using media to let the child behave well or to comply with restrictions may have positive outcomes on the short run, but it is doubtful whether children will indeed learn moral codes intrinsically.

In order to organize more practical parenting advise, more research on media use within the family is needed. One line of research could focus on the instrumental use of media by less confident or stressed parents. Especially, insecure parents of younger children could be advised to think about different forms of instrumental use of media, and the associated risks and benefits. Providing them with alternative activities such as reading, playing or drawing, instead of screen use, for instance, may help to curb extended use of media before the child grows older. Another line of research could focus on the types of media content that parents provide their child with when they need some time for themselves and rely on media as a distractor, or when they are themselves occupied and use media as a babysitter, or when they want to modify their child's behavior. Such studies should specifically focus on how parents may be convinced of the educational benefits of media for their children (Beyens and Eggermont 2017). Contemporary media are very well capable of keeping the child occupied and at the same time teach them new concepts, words or numbers (e.g., Fisch 2014). Professionals who support parents in childrearing could benefit from the outcomes of such studies, by raising more awareness among parents about the potential negative and positive outcomes of media use for their child and for the parent, eventually contributing positively to, for example, reading, school achievement, or health gains in these children.

\section{Limitations}

The survey used in this study was deliberately kept concise to prevent respondents dropping out from the study. A shortcoming of this study, therefore, is the limited amount 
of items used to measure the instrumental use of media devices in parenting. As mentioned before, future studies could replicate this study with an extended list of items that tap various ways of instrumental media use by parents at home or outside the house and for various reasons. Another point of interest is that on average a minority of the parents reported a lack of confidence in their parenting abilities and a lack of support from a spouse or (ex)partner. Also only a small portion of the parents had a child with a developmental problem. The skewed distribution of these variables may have influenced the strength of the results in the regression analyses. Also this study did not ask parents about their work or more specifically about perceived timepressure. Qualitative studies among selected families that represent depressed, stressed or overworked parents may provide more in-depth information about the parent's reasons to use media devices as a tool in their childrearing. I think that the relationships that appeared in this study between parental views on their parenting situation and the use of media devices as a tool in childrearing provide an interesting starting point for such future work.

Acknowledgements This study has been made possible by stichting Opvoeden.nl [Childrearing.nl foundation] and Inge Markx, MS who has executed the preliminary pilot study as part of her Master's thesis for Utrecht University.

\section{Compliance with Ethical Standards}

Conflict of Interest The author declares that he has no conflict of interest.

Open Access This article is distributed under the terms of the Creative Commons Attribution 4.0 International License (http://crea tivecommons.org/licenses/by/4.0/), which permits use, duplication, adaptation, distribution, and reproduction in any medium or format, as long as you give appropriate credit to the original author(s) and the source, provide a link to the Creative Commons license, and indicate if changes were made.

\section{References}

AAP Council. (2016). Media and young minds. Pediatrics, AAP News and Journals Council on Communications and Media. http:// pediatrics.aappublications.org/content/early/2016/10/19/peds. 2016-2591.

Acosta, R.M., \& Hutchinson, M. (2017). They raise the world's happiest children-so is it time you went Dutch? The Telegraph, January 17, 2017. Accessed 17 August 2017 from: http://www. telegraph.co.uk/women/family/raise-worlds-happiest-childrentime-went-dutch/.

Aldous, J., \& Klein, D. M. (1991). Sentiment and services: models of intergenerational relationships in mid-life. Journal of Marriage and the Family, 53(3), 595-608.

Beyens, I., \& Eggermont, S. (2014). Putting young children in front of the television: antecedents and outcomes of parents' use of television as a babysitter. Communication Quarterly, 62(1), 57-74.
Beyens, I., \& Eggermont, S. (2017). Understanding children's television exposure from a life logistics perspective: a longitudinal study of the association between mothers' working hours and young children's television time. Communication Research, 44 (5), 691-716.

Bornstein, M. H., Hendricks, C., Hahn, C. S., Haynes, O. M., Painter, K. M., \& Tamis-LeMonda, C. S. (2003). Contributors to selfperceived competence, satisfaction, investment, and role balance in maternal parenting: a multivariate ecological analysis. Parenting: Science and Practice, 3(4), 285-326.

de Brock, A. J. L. L., Vermulst, A. A., Gerris, J. R. M., \& Abidin, R. R. (1992). NOSI, Nijmeegse Ouderlijke Stress Index. Experimentele versie. Handleiding. [NOSI, Nijmegen Parental Stress Index. Experimental version. Manual]. Lisse: Swets \& Zeitlinger.

Caceres-Delpiano, J. (2006). The impacts of family size on investment in child quality. Journal of Human Resources, 49(4), 738-754.

Cain, S., \& Combs-Orme, T. (2005). Family structure effects on parenting stress and practices in the African American family. The Journal of Sociology \& Social Welfare, 32(2), 19-40.

Campbell, K., Hesketh, K., Silverii, A., \& Abbott, G. (2010). Maternal self-efficacy regarding children's eating and sedentary behaviours in the early years: associations with children's food intake and sedentary behaviours. International Journal of Pediatric Obesity, 5, 501-508.

CBS (2014). Bevolking; hoogst behaald onderwijsniveau; geslacht, leeftijd en herkomst [Population; highest attained level of education; gender, age and country of birth]. Retrieved from: http:// statline.cbs.nl/Statweb/publication/?DM $=$ SLNL\&PA $=$ $82275 \mathrm{NED} \& \mathrm{D} 1=0 \& \mathrm{D} 2=0 \& \mathrm{D} 3=0 \& \mathrm{D} 4=0-1,4-5 \& \mathrm{D} 5=0,2-4,8-$ $10,12-14 \& \mathrm{D} 6=59,65-68,70-71 \& \mathrm{HDR}=\mathrm{T}, \mathrm{G} 5, \mathrm{G} 3, \mathrm{G} 1 \& \mathrm{STB}=\mathrm{G} 2$, $\mathrm{G} 4 \& \mathrm{VW}=\mathrm{T}$.

Chiong, C., \& Shuler, C. (2010). Learning: is there an app for that? Investigations of young children's usage and learning with mobile devices and apps. New York: The Joan Ganz Cooney Center at Sesame Workshop.

Cingel, D., \& Krcmar, M. (2013). Predicting media use in very young children: the role of demographic and parent attitudes. Communication Studies, 64(4), 374-394.

Conners, N. A., Tripathi, S. P., Clubb, R., \& Bradley, R. H. (2007). Maternal characteristics associated with television viewing habits of low-income preschool children. Journal of Child \& Family Studies, 16, 415-425. https://doi.org/10.1007/s10826-006-90950 .

Crnic, K. A., Gaze, C., \& Hoffman, C. (2005). Cumulative parenting stress across the preschool period: relations to maternal parenting and child behavior at age five. Infant and Child Development, 14, $117-132$

Dodge, K. A., Pettit, G. S., \& Bates, J. E. (1994). Socialization mediators of the relation between socioeconomic status and child conduct problems. Child Development, 65(2), 649-665.

Elias, N., \& Sulkin, I. (2017). YouTube viewers in diapers: an exploration of factors associated with amount of toddlers' online viewing. Cyberpsychology: Journal of Psychosocial Research on Cyberspace, 11(3), article 2 https://doi.org/10.5817/CP2017-3-2.

Etta, R., Horgan, E.S., \& Kirkorian, H. (2018 forthcoming). Turning the page on children's book use: parent perceptions of eBooks and print books. In J.E. Kim \& B. Hassinger-Das (Eds.) Reading in the digital age: young children's experiences with E-books. London: Springer.

Evans, C. A., Jordan, A. B., \& Horner, J. (2011). Only two hours? a qualitative study of the challenges parents perceive in restricting child television time. Journal of Family Issues, 32(9), 1223-1244.

Fisch, S. M. (2014). Children's learning from educational television: Sesame Street and beyond. NY: Routledge. 
Giallo, R., Treyvaud, K., Cooklin, A., \& Wade, C. (2013). Mothers' and fathers' involvement in home activities with their children: psychosocial factors and the role of parental self-efficacy. Early Child Development and Care, 183(3-4), 343-359. https://doi.org/ 10.1080/03004430.2012.711587.

Gantz, W. (1982). Television the surrogate parent: uses and correlates of television as babysitter. Paper presented at the annual meeting of the Association for Education in Journalism. Athens. Retrieved on August 21, 2017 from: http://files.eric.ed.gov/fulltext/ ED218650.pdf.

Gordon, J. R., \& Whelan-Berry, K. S. (2004). It takes two to tango: an empirical study of perceived spousal/partner support for working women. Women in Management Review, 19(5), 260-273.

Götz, M., Bachmann, S., \& Hofmann, O. (2007). Just a babysitter? TeleVizion, 20, 35-39.

Hoff, E., Laursen, B., \& Tardif, T. (2002). Socioeconomic status and parenting. In M. H. Bornstein (Ed), Handbook of parenting (2nd edn., pp. 231-252). Mahwah: Lawrence Erlbaum Associates.

Jago, R., Wood, L., Zahra, J., Thompson, J. L., \& Sebire, S. J. (2015). Parental control, nurturance, self-efficacy, and screen viewing among 5- to 6-year-old children: a cross-sectional mediation analysis to inform potential behavior change strategies. Childhood Obesity, 11(2), 139-147.

Livingstone, S., Haddon, L., Görzig, A., \& Ólafsson, K. (2011). Risks and safety on the internet: the perspective of European children: full findings and policy implications from the EU Kids Online survey of 9-16 year olds and their parents in 25 countries. London: EU Kids Online.

Livingstone, S., \& Helsper, E. (2008). Parental mediation and children's Internet use. Journal of Broadcasting \& Electronic Media, 52(4), 581-599.

Livingstone, S., Mascheroni, G., Dreier, M., Chaudron, S., \& Lagae, K. (2015). How parents of young children manage digital devices at home: the role of income, education and parental style. London: EU Kids Online.

Lull, J. (1980a). The social uses of television. Human Communication Research, 6(3), 197-209. https://doi.org/10.1111/j.1468-2958. 1980.tb00140.x.

Lull, J. (1980b). Family communication patterns and the social uses of television. Communication Research, 7(3), 319-333. https://doi. org/10.1177/009365028000700303.

Machida, S., Taylor, A., \& Kim, J. (2002). The role of maternal beliefs in predicting home learning activities in head start families. Family Relations, 51, 176-184.

Mares, M. L., Stephenson, L., Martins, N., \& Nathanson, A. I. (2018). A house divided: parental disparity and conflict over media rules predict children's outcomes. Computers in Human Behavior, 18, 177-188. https://doi.org/10.1016/j.chb.2017.12.009.

Mather, M. (2010). US Children in single-mother families. Data brief. Washington, DC: Population Reference Bureau.

McBride, B. A., \& Mills, G. (1993). A comparison of mother and father involvement with their preschool age children. Early Childhood Research Quarterly, 8, 457-477.

McLoyd, V. (1998). Socioeconomic disadvantage and child development. American Psychologist, 53(2), 185-204.

Mendoza, K. (2009). Surveying parental mediation: connections, challenges and questions for media literacy. The Journal of Media Literacy Education, 1(1), 28-41.

Morley, D. (1986). Family television: cultural power and domestic leisure. London: Routledge..

Nabi, R. L., \& Krcmar, M. (2016). It takes two: the effect of child characteristics on U.S. parents' motivations for allowing electronic media use. Journal of Children and Media, 10(3), 285-303.

Nikken, P. (2017). Implications of low or high media use among parents for children's media use. Cyberpsychology: Journal of
Psychosocial Research on Cyberspace, 11(3), article 1 https://doi. org/10.5817/CP2017-3-1.

Nikken, P., \& de Haan, J. (2015). Guiding young children's internet usage at home: problems that parents experience in their parental mediation and the need for parenting support. Cyberpsychology: Journal of Psychosocial Research on Cyberspace, 9(1). https:// doi.org/10.5817/CP2015-1-3

Nikken, P., \& Jansz, J. (2014). Developing scales to measure parental mediation of young children's internet use. Learning, Media and Technology, 39(2), 250-266. https://doi.org/10.1080/17439884. 2013.782038.

Nikken, P., \& Schols, M. (2015). How and why parents guide the media use of young children. Journal of Child and family Studies, 24(11), 3423-3435. https://doi.org/10.1007/s10826-015-0144-4.

Nomaguchi, K. M. (2009). Change in work-family conflict among employed parents between 1977 and 1999. Journal of Marriage and Family, 71(1), 15-32.

Ofcom (2017). Children and parents: media use and attitudes report. London: Ofcom.

Pearlin, L. I. (1989). The sociological study of stress. Journal of Health and Social Behavior, 30(3), 241-256. https://doi.org/10. 2307/2136956.

Pearson, N., Salmon, J., Crawford, D., Campbell, K., \& Timperio, A. (2011). Are parental concerns for child TV viewing associated with child TV viewing and the home sedentary environment? International Journal of Behavioral Nutrition and Physical Activity, 8, 102 https://doi.org/10.1186/1479-5868-8-102.

Persegani, C., Russo, P., Carucci, C., Micolini, M., Papeschi, L. L., \& Trimarchi, M. (2002). Television viewing and personality structure in children. Personality and Individual Differences, 32(6), 977-990. https://doi.org/10.1016/S0191-8869(01)00102-7.

Piotrowski, J., Jordan, A., Bleakley, A., \& Hennessy, M. (2015). Identifying family media practices to reduce children's television time. Journal of family Communication, 15(2), 159-174.

Radesky, J. S., Silverstein, M., Zuckerman, B., \& Christakis, D. A. (2014). Infant self-regulation and early childhood media exposure. Pediatrics, 133(5), e1172-e1178.

Rasmussen, E., Shafer, A., Colwell, M., White, S., Punyanunt-Carter, N., Densley, R., \& Wright, H. (2016). Relation between active mediation, exposure to Daniel Tiger's Neighborhood, and US preschoolers' social and emotional development. Journal of Children and Media, 10(4), 443-461.

Rideout, V. (2017). The Common Sense Census: media use by kids zero to eight. San Fransico, CA: Common Sense Media.

Rideout, V., \& Hamel, E. (2006). The media family: electronic media in the lives of infants, toddlers, preschoolers and their parents. Menlo Park, California: Electronic Media.

Rubin, A. M. (1986). Uses, gratifications, and media effects research. In J. Bryant, \& D. Zillmann (Eds.), Perspectives on media effects (pp. 281-301). Hillsdale, NJ: Lawrence Erlbaum Associates.

Smith, B. J., Grunseit, A., Hardy, L. L., King, Wolfenden, L., \& Milat, A. (2010). Parental influences on child physical activity and screen viewing time: a population based study. BMC Public Health, 10, 593 1186/1471-2458-10-593.

Staal, I. I. E., van den Brink, H. A. G., Hermanns, J. M. A., Schrijvers, A. J. P., \& van Stel, H. F. (2011). Assessment of parenting and developmental problems in toddlers: development and feasibility of a structured interview. Child Care, Health \& Development, 37 (4), 503-511.

Satherley, D. (2017). Elsagate: the disturbing YouTube trend that might be terrifying your children. November 24, 2017. Downloaded from https://www.newshub.co.nz/home/entertainment/ 2017/11/elsagate-the-disturbing-youtube-trend-that-might-beterrifying-your-children.html, Accessed on 12 June 2018.

Tabachnick, B. G., \& Fidell, L. S. (2007). Using multivariate statistics (5th edn.) Essex, UK: Pearson. 
Tourangeau, R., \& Yan, T. (2007). Sensitive questions in surveys. Psychological Bulletin, 133(5), 859-883. https://doi.org/10.1037/ 0033-2909.133.5.859.

Walton, K., Simpson, J. R., Darlington, G., \& Haines, J. (2014). Parenting stress: a cross-sectional analysis of associations with childhood obesity, physical activity, and TV viewing. BMC Pediatrics, 14, 244 https://doi.org/10.1186/1471-2431-14-244.

Warren, R. (2005). Parental mediation of children's television viewing in low-income families. Journal of Communication, 55(4), $847-863$.

Wartella, E., Rideout, V., Lauricella, A.R., \& Connell, S.L. (2014). Revised. Parenting in the age of digital technology: a national survey. Evanston, IL: Center on Human Development, Northwestern University.

Zaman, B., Nouwen, M., Vanattenhoven, J., de Ferrerre, E., \& Van looy, J. (2016). A qualitative inquiry into the contextualized parental mediation practices of young children's digital media use at home. Journal of Broadcasting and Electronic Media, 60(1), $1-22$.

Zimmerman, F. J., Christakis, D. A., \& Meltzoff, A. N. (2007). Television and DVD/video viewing in children younger than 2 years. Archives of Pediatrics \& Adolescent Medicine, 161(5), 473-479. 